\title{
Iron and cobalt complexes of 4,4,9,9-tetramethyl-5,8-diazadodecane-2, 11-dione dioxime ligand: Synthesis, characterization and reactivity studies
}

\author{
OINDRILA DAS, SAYANTI CHATTERJEE and TAPAN KANTI PAINE* \\ Department of Inorganic Chemistry, Indian Association for the Cultivation of Science, 2A and 2B, \\ Raja S C Mullick Road, Jadavpur, Kolkata 700032, India \\ e-mail: ictkp@iacs.res.in
}

\begin{abstract}
Two oximate bridged dinuclear complexes $\left[\mathrm{Co}_{2}^{\mathrm{II}}(\mathrm{HL})_{2}\right]\left(\mathrm{ClO}_{4}\right)_{2}(\mathbf{1})$ and $\left[\mathrm{Fe}_{2}^{\mathrm{II}}(\mathrm{HL})_{2}\right]\left(\mathrm{ClO}_{4}\right)_{2}(\mathbf{2})$, and a biomimetic iron(III)-catecholate complex $\left[\mathrm{Fe}^{\mathrm{III}}(\mathrm{HL})(\mathrm{DBC})\right](3)$ of a dioxime ligand $\left(\mathrm{H}_{2} \mathrm{~L}=4,4,9,9\right.$ tetramethyl-5,8-diazadodecane-2,11-dione dioxime and $\mathrm{DBCH}_{2}=3,5$-di-tert-butylcatechol) were synthesized and characterized. X-ray single-crystal structures of both the dinuclear complexes exhibit an out-of-plane oximate bridge where the six-membered $\mathrm{M}_{2}(\mathrm{NO})_{2}$ ring adopt a boat conformation with the metal ions in a fivecoordinate distorted trigonal bipyramidal geometry. Complexes $\mathbf{1}$ and $\mathbf{2}$ react with dioxygen at ambient condition to form the corresponding hydroxo- or oxo-bridged dinuclear cobalt(III) or iron(III) complexes. On the other hand, the iron(III)-catecholate complex (3) activate dioxygen to undergo oxidative $\mathrm{C}-\mathrm{C}$ bond cleavage of catechol. The selective formation of extradiol catechol cleavage products in the reaction of $\mathbf{3}$ with dioxygen mimics the functional aspect of extradiol-cleaving catechol dioxygenases. The flexibility of ligand backbone is proposed to control the dioxygen reactivity of metal complexes.
\end{abstract}

Keywords. Iron; cobalt; oximate ligand; oxidation; catechol cleavage; solid-state structure.

\section{Introduction}

Oximes and dioximes are extensively used for the synthesis of exchange coupled polynuclear metal complexes relevant to molecular magnetic materials. ${ }^{1}$ Oximate ligands show different binding modes to stabilize structurally and magnetically interesting transition metal complexes. ${ }^{1-11}$ Additionally, studies on the reactivity of metal-coordinated oximates have attracted much attention in coordination chemistry. ${ }^{12-16}$ We have recently reported the structure and magnetic properties of dinickel(II) and dicopper(II) complexes derived from a $\beta$-aminoketoxime ligand, 4,4,9,9-tetramethyl-5,8diazadodecane-2,11-dione dioxime $\left(\mathrm{H}_{2} \mathrm{~L}\right)$ (chart 1). ${ }^{17}$ The nickel(II) complexes have been shown to undergo a proton-assisted coupling of oxime with nitriles resulting in the iminoacylation of oxime $\mathrm{H}_{2} \mathrm{~L}$. The dioxime ligand forms complexes with other metal ions like iron(II), cobalt(II), and zinc(II) ions. ${ }^{18-20}$ The flexible N4 ligand is expected to stabilize mononuclear complexes in the presence of a bidentate coligand. This

\footnotetext{
*For correspondence
}

would therefore find application in biomimetic chemistry for designing model complexes. As a part of our ongoing study in this direction, we report in this paper the synthesis and structures of two oximate bridged dinuclear metal complexes $\left[\mathrm{Co}_{2}^{\mathrm{II}}(\mathrm{HL})_{2}\right]\left(\mathrm{ClO}_{4}\right)_{2}(\mathbf{1})$ and $\left[\mathrm{Fe}_{2}^{\mathrm{II}}(\mathrm{HL})_{2}\right]\left(\mathrm{ClO}_{4}\right)_{2}(\mathbf{2})$. We also report the isolation and characterization of a biomimetic iron(III)-catecholate complex, [Fe $\left.\mathrm{Fe}^{\mathrm{III}}(\mathrm{HL})(\mathrm{DBC})\right](3)$ as model for catecholcleaving dioxygenases. The reactivity of metal complexes of oximate ligand towards dioxygen and the<smiles>CC(CC(C)(C)NCCNC(C)(C)CC(C)=NO)=NO</smiles>

$\mathrm{H}_{2} \mathrm{~L}$<smiles>CC(C)(C)c1cc(O)c(O)c(C(C)(C)C)c1</smiles>

$\mathrm{DBCH}_{2}$
Chart 1. Ligands. 
nature of oxidative catechol cleavage products from the iron(III)-catecholate complex are discussed.

\section{Experimental}

Commercial grade chemicals were used for synthetic purposes. Solvents were distilled, dried and deoxygenated before use. Preparation and handling of airsensitive compounds were carried out under an inert atmosphere in a glove box. Although no problem was encountered during the synthesis of the complexes, perchlorate salts are potentially explosive and should be handled with care! ${ }^{21}$ The ligand, 4,4,9,9-tetramethyl5,8-diazadodecane-2,11-dione dioxime $\left(\mathrm{H}_{2} \mathrm{~L}\right)$, was synthesized according to a literature procedure. ${ }^{22}$ Fourier transform infrared spectroscopy on $\mathrm{KBr}$ pellets was performed on a Shimadzu FT-IR 8400S instrument. Elemental analyses were performed on a Perkin Elmer 2400 series II CHN analyzer. Electro-spray ionization (ESI) mass spectra were recorded with a Waters QTOF Micro YA263 instrument. Solution electronic spectra were measured on an Agilent 8453 diode array spectrophotometer. Room temperature ${ }^{1} \mathrm{H}$ NMR spectra were collected on a Bruker DPX-500 spectrometer. Room temperature magnetic data were collected on a Gouy balance (Sherwood Scientific, Cambridge, UK). Diamagnetic contributions were estimated for each compound by using Pascal's constants.

\subsection{Synthesis of the complexes}

2.1a $\left[\mathrm{Co}_{2}^{\mathrm{II}}(\mathrm{HL})_{2}\right]\left(\mathrm{ClO}_{4}\right)_{2}(\mathbf{1})$ : To a methanolic solution $(10 \mathrm{~mL})$ of $\mathrm{Co}\left(\mathrm{ClO}_{4}\right)_{2} \cdot 6 \mathrm{H}_{2} \mathrm{O}(0.11 \mathrm{~g}, 0.3 \mathrm{mmol})$, ligand $(0.086 \mathrm{~g}, 0.3 \mathrm{mmol})$ was added. A pink solution was formed immediately which was stirred at room temperature for $3 \mathrm{~h}$ under nitrogen to precipitate a pink solid. The pink precipitate was isolated by filtration, redissolved in methanol and kept for layer diffusion with diethyl ether. Pink plate-shaped crystals suitable for $\mathrm{X}$-ray diffraction were isolated after a few days. Yield: $0.073 \mathrm{~g}$ (55\%). Anal. Calcd for $\mathrm{C}_{28} \mathrm{H}_{58} \mathrm{Cl}_{2} \mathrm{Co}_{2} \mathrm{~N}_{8} \mathrm{O}_{12}$ (887.58 g/mol): C, 37.89; H, 6.59; N, 12.62. Found: C, 38.02; H, 6.27; N, 12.58\%. IR $\left(\mathrm{KBr}, \mathrm{cm}^{-1}\right)$ : 3433(br), 3262(m), 32110(m), 3075(w), 2970(w), 2731(w), 1663(w), 1626(w), 1468(m), 1371(s), 12771202(w), 1146-1090(vs), 1003(m), 947(m), 855(m), 773(w), 696(m), 625(s). ESI-MS (positive ion mode, $\mathrm{MeCN}): m / z=343.13\left(100 \%,[\mathrm{~L}+\mathrm{Co}]^{+}\right)$. UV-Vis in $\mathrm{MeCN}: \lambda, \mathrm{nm}\left(\varepsilon, \mathrm{M}^{-1} \mathrm{~cm}^{-1}\right): 550$ (44). Magnetic moment $(298 \mathrm{~K}): \mu_{\mathrm{eff}}=4.25 \mu_{\mathrm{B}}$. 2.1b $\left[\mathrm{Fe}_{2}^{I I}(\mathrm{HL})_{2}\right]\left(\mathrm{ClO}_{4}\right)_{2}(2)$ : Complex 2 was synthesized according to a protocol described for complex 1 except that iron(II) perchlorate was used instead of cobalt(II) perchlorate. A white solid was isolated at the end of the reaction. The white solid was dissolved in a solvent mixture of dichloromethane and acetonitrile (1:1) mixture and kept for layer diffusion with diethyl ether to obtain colourless crystals of $\mathbf{2}$ suitable for X-ray diffraction. Yield: $0.093 \mathrm{~g}$ (70\%). Anal. Calcd for $\mathrm{C}_{28} \mathrm{H}_{58} \mathrm{Cl}_{2} \mathrm{Fe}_{2} \mathrm{~N}_{8} \mathrm{O}_{12}(881.42 \mathrm{~g} / \mathrm{mol})$ : C, 38.16; H, 6.63; N, 12.71. Found: C, 38.04; H, 6.46; N, $12.43 \%$. IR (KBr, $\left.\mathrm{cm}^{-1}\right): 3416(\mathrm{br}), 3248(\mathrm{~s})$, 3088(w), 2974-2878(s), 2735(w), 1663(w), 1626(w) 1468(m), 1420(m) 1371(s), 1280-1232(w), 11631094(vs), 1018(w), 995(m), 943(m), 851(m), 777(w), 696(m), 625(s). ESI-MS (positive ion mode, MeCN): $m / z=287.10\left(100 \%,\left[\mathrm{H}_{2} \mathrm{~L}+\mathrm{H}\right]^{+}\right)$. UV-Vis in MeCN: $\lambda, \mathrm{nm} ;\left(\varepsilon, \mathrm{M}^{-1} \mathrm{~cm}^{-1}\right): 380$ (sh). Magnetic moment $(298 \mathrm{~K}): \mu_{\mathrm{eff}}=6.81 \mu_{\mathrm{B}}$.

2.1c $\left[F e^{I I I}(H L)(D B C)\right](3): \quad$ To a solution of ligand $(0.143 \mathrm{~g}, 0.5 \mathrm{mmol})$ in methanol $(5 \mathrm{~mL})$, was added a methanolic solution $(10 \mathrm{~mL})$ of $\mathrm{Fe}\left(\mathrm{ClO}_{4}\right)_{3} \cdot \mathrm{xH}_{2} \mathrm{O}$ $(0.177 \mathrm{~g}, 0.5 \mathrm{mmol})$. The resulting orange solution was treated with a mixture of 3,5-di-tert-butylcatechol $(0.11 \mathrm{~g}, \quad 0.5 \mathrm{mmol})$ and triethylamine $(128 \mu \mathrm{L}$, $1 \mathrm{mmol})$ in methanol $(2 \mathrm{~mL})$. The solution was immediately turned to deep blue. The clear reaction mixture was stirred for $6 \mathrm{~h}$ and then solvent was removed to dryness. The solid residue was washed several times with distilled water and finally with diethyl ether to obtain a purple-blue powder. Yield: $0.26 \mathrm{~g}$ (93\%). Anal. Calcd for $\mathrm{C}_{28} \mathrm{H}_{49} \mathrm{FeN}_{4} \mathrm{O}_{4}(561.56 \mathrm{~g} / \mathrm{mol})$ : C, 59.89; H, 8.80; N, 9.98. Found: C, 59.64; H, 8.72; N, 9.79\%. IR (KBr, cm $\left.{ }^{-1}\right)$ : 3430(br), 2953-2868 (vs), 1624(w), 1585(w), 1550(w), 1464(s), 1414(s), 1360(m), 1310(w), 1277(w), 1247(s), 1205(w), 1173(w), 1115(s), 1028(w), 980(s), 858(w), 829(w), 746, 679. ESI-MS (positive ion mode, MeCN): $m / z=$ $562.89\left(10 \%,[\mathrm{Fe}(\mathrm{HL})(\mathrm{DBC})+\mathrm{H}]^{+}\right), 287.10(100 \%$, $\left.\left[\mathrm{H}_{2} \mathrm{~L}+\mathrm{H}\right]^{+}\right)$. UV-Vis in MeCN: $\lambda, \mathrm{nm}\left(\varepsilon, \mathrm{M}^{-1} \mathrm{~cm}^{-1}\right)$ : 665 (1920). Magnetic moment (298): $\mu_{\text {eff }}=5.85 \mu_{\mathrm{B}}$.

\subsection{Analysis of the catechol cleavage products}

The iron-catecholate complex $(0.05 \mathrm{mmol})$ was dissolved in oxygen saturated acetonitrile $(15 \mathrm{~mL})$ and stirred for $12 \mathrm{~h}$ at room temperature. The blue solution was changed slowly to light green. The solvent was then removed under vacuum and the residue was treated 
with $3 M$ hydrochloric acid $(10 \mathrm{~mL})$. The organic products were extracted with diethyl ether $(3 \times 15 \mathrm{~mL})$ and the organic fraction was dried over anhydrous sodium sulphate. The catechol derived products were analysed by ${ }^{1} \mathrm{H}-\mathrm{NMR}$ spectroscopy without further purification. The spectral data were compared with the reported data for authentic extradiol and intradiol cleavage products. ${ }^{23-27}{ }^{1} \mathrm{H}$-NMR data for 3,5-di-tert-butylcatechol cleavage products $\left(500 \mathrm{MHz}, \mathrm{CDCl}_{3}, 295 \mathrm{~K}\right)$ : 4,6-ditert-butyl-2-pyrone (A): $\delta=1.22(\mathrm{~s}, 9 \mathrm{H}), 1.36(\mathrm{~s}, 9 \mathrm{H})$, $6.05(\mathrm{~m}, 2 \mathrm{H}) ; 3,5$-di-tert-butyl-2-pyrone $(\mathbf{B}): \delta=1.22$ (s, 9H), 1.40 (s, 9H), $7.21(\mathrm{~d}, 1 \mathrm{H}), 7.24(\mathrm{~d}, 1 \mathrm{H})$; 3,5-ditert-butyl-5-(carboxymethyl)-2-furanone $(\mathbf{C}): \delta=0.98$ (s, 9H), 1.24 (s, 9H), $2.91(\mathrm{~d}, 1 \mathrm{H}), 2.81(\mathrm{~d}, 1 \mathrm{H}), 6.96(\mathrm{~s}$, 1H), 9.72 (s, 1H); 3,5-di-tert-butylbenzoquinone (D): $\delta=1.22(\mathrm{~s}, 9 \mathrm{H}), 1.28(\mathrm{~s}, 9 \mathrm{H}), 6.21(\mathrm{~d}, 1 \mathrm{H}), 6.93(\mathrm{~d}, 1 \mathrm{H})$.

\subsection{X-ray crystallographic studies}

X-ray single crystal data were collected at $298 \mathrm{~K}$ using Mo-K $\mathrm{K}_{\alpha}(\lambda=0.7107 \AA)$ radiation on a SMART APEX-II diffractometer equipped with CCD area detector. Crystallographic data for $\mathbf{1}$ and $\mathbf{2}$ are provided in table
1. Data collection, data reduction, and structure solution/refinement were carried out using the software package of APEX II. ${ }^{28}$ All structures were solved by direct method and refined in a routine manner. All the non-hydrogen atoms were refined anisotropically and all the hydrogen atoms were fixed geometrically. In both the complexes (1 and $\mathbf{2}$ ), some disordered electron densities were located in the asymmetric unit at the end of the refinement cycles. SQUEEZE calculation indicated the presence of 80 and 127 electron densities per unit cell for $\mathbf{1}$ and $\mathbf{2}$, respectively. The final full matrix least squares refinement converged to $R_{1}=0.0473$ and $w \mathrm{R}_{2}=0.1218$ for $\mathbf{1}$, and $R_{1}=0.0475$ and $w \mathrm{R}_{2}=$ $0.1321\left(F^{2}\right.$, all data) for 2 .

\section{Results and discussion}

Reactions of ligand $\mathrm{H}_{2} \mathrm{~L}$ and equimolar amounts of cobalt(II) perchlorate or iron(II) perchlorate in methanol at ambient conditions under nitrogen atmosphere yield the respective metal complexes, $\left[\mathrm{Co}_{2}^{\mathrm{II}}(\mathrm{HL})_{2}\right]\left(\mathrm{ClO}_{4}\right)_{2}(\mathbf{1})$ and $\left[\mathrm{Fe}_{2}^{\mathrm{II}}(\mathrm{HL})_{2}\right]\left(\mathrm{ClO}_{4}\right)_{2}(\mathbf{2})$. The iron(III)-catecholate complex, [Fe $\left.{ }^{\mathrm{III}}(\mathrm{HL})(\mathrm{DBC})\right](\mathbf{3})$ is synthesized in high yield by reacting the ligand with

Table 1. Crystallographic data for complexes $\mathbf{1}$ and $\mathbf{2}$.

\begin{tabular}{|c|c|c|}
\hline & 1 & 2 \\
\hline Empirical formula & $\mathrm{C}_{28} \mathrm{H}_{58} \mathrm{Cl}_{2} \mathrm{Co}_{2} \mathrm{~N}_{8} \mathrm{O}_{12}$ & $\mathrm{C}_{28} \mathrm{H}_{58} \mathrm{Cl}_{2} \mathrm{Fe}_{2} \mathrm{~N}_{8} \mathrm{O}_{12}$ \\
\hline Formula weight & 887.58 & 881.42 \\
\hline Crystal system & Monoclinic & Monoclinic \\
\hline Space group & $C 2 / c$ & $C 2 / c$ \\
\hline$a / \AA$ & $22.01(3)$ & $20.831(6)$ \\
\hline$b / \AA$ & $12.689(17)$ & $13.670(4)$ \\
\hline$c / \AA$ & $16.82(2)$ & $16.562(7)$ \\
\hline$\alpha /^{0}$ & 90.00 & 90.00 \\
\hline$\beta /{ }^{0}$ & $108.81(3)$ & $106.129(9)$ \\
\hline$\gamma /{ }^{0}$ & 90.00 & 90.00 \\
\hline Volume $/ \AA^{3}$ & $4445(11)$ & $4531(3)$ \\
\hline$Z$ & 4 & 4 \\
\hline $\mathrm{D}_{\text {calc }} / \mathrm{gcm}^{-3}$ & 1.326 & 1.292 \\
\hline$F(000)$ & 1864 & 1856 \\
\hline$\mu \mathrm{MoK}_{\alpha} / \mathrm{mm}^{-1}$ & 0.925 & 0.816 \\
\hline Temperature/K & 298(2) & $298(2)$ \\
\hline $\mathrm{R}_{\text {int }}$ & 0.0809 & 0.0893 \\
\hline Range of $h, k, 1$ & $-19 / 19,-11 / 11,-15 / 15$ & $-21 / 21,-14 / 14,-17 / 16$ \\
\hline$\theta \min / \max /{ }^{\circ}$ & $1.88 / 18.72$ & $1.80 / 22.13$ \\
\hline Reflections collected/unique/observed $[I>2 \sigma(I)]$ & $7783 / 1694 / 1251$ & $15499 / 2761 / 2073$ \\
\hline Data/restraints/ Parameters & $1694 / 0 / 242$ & $2761 / 0 / 250$ \\
\hline Goodness of fit on $F^{2}$ & 0.881 & 0.867 \\
\hline Final $\mathrm{R}$ indices $[I>2 \sigma(I)]^{\mathrm{a}}$ & $\mathrm{R}_{1}=0.0473$ & $\mathrm{R}_{1}=0.0475$ \\
\hline & $\mathrm{wR}_{2}=0.1218$ & $\mathrm{wR}_{2}=0.1321$ \\
\hline
\end{tabular}

${ }^{\mathrm{a}} R_{1}=\Sigma|| F \mathrm{o}|-| F \mathrm{c}|| / \Sigma|F \mathrm{o}|, w R_{2}=\left[\Sigma w\left(F \mathrm{o}^{2}-F \mathrm{c}^{2}\right)^{2} / \Sigma w\left(F \mathrm{o}^{2}\right)^{2}\right]^{1 / 2}$ 


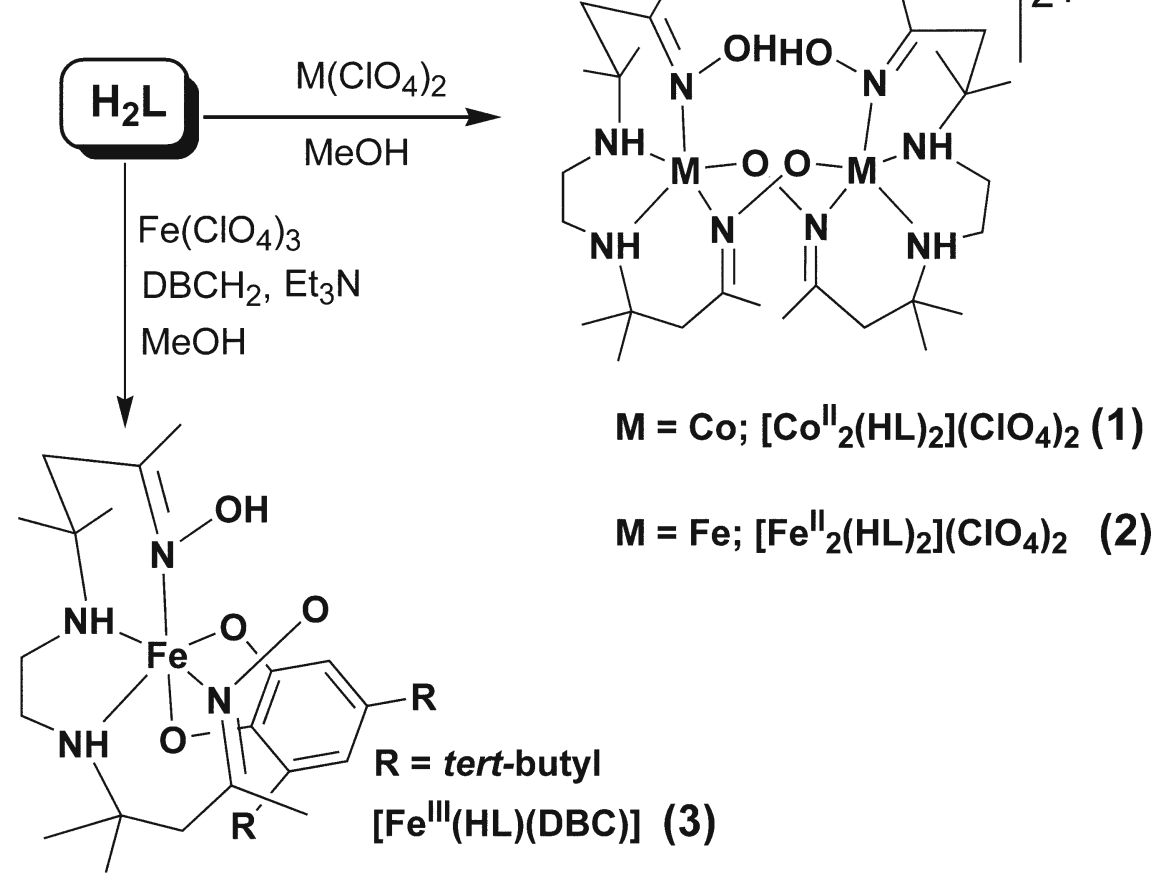

Scheme 1. Synthesis of complexes.

iron(III) perchlorate and 3,5-di-tert-butylcatechol in methanol in the presence of triethylamine (scheme 1). The presence of strong and broad bands due to perchlorate ions at around $1165-1085 \mathrm{~cm}^{-1}$ and at $625 \mathrm{~cm}^{-1}$ in the IR spectra suggest the cationic nature of $\mathbf{1}$ and 2. Complexes 1 and $\mathbf{2}$ show characteristic sharp N-H bands of the ligand in the region $3260-3210 \mathrm{~cm}^{-1}$ indicating the binding of ligand with the metal ions. The bands for perchlorate ions are absent in the IR spectrum of $\mathbf{3}$, indicating a neutral complex. The ligation of 3,5-di-tert-butylcatechol anion to the metal centre in $\mathbf{3}$ is supported by the presence of strong and sharp bands in the region of $2955-2868 \mathrm{~cm}^{-1}$.
ESI-mass spectra (positive ion mode in acetonitrile) exhibit ion peaks at $m / z=343.13$ for $\mathbf{1}$ and at $\mathrm{m} / z=$ 287.10 for 2 attributable to $[\mathrm{L}+\mathrm{Co}]^{+}$and $\left[\mathrm{H}_{2} \mathrm{~L}+\mathrm{H}\right]^{+}$, respectively. ESI-MS data indicate the decomposition of dimeric complexes in the experimental condition of mass spectrometry. On the other hand, ESI-mass spectrum of 3 shows ion peak at $m / z=562.89$ with expected isotope distribution pattern calculated for $[\mathrm{Fe}(\mathrm{HL})(\mathrm{DBC})+\mathrm{H}]^{+}$. This further supports the neutral nature of the complex. All the complexes are stable in the solid state under nitrogen atmosphere. Room temperature magnetic moment values of $4.25 \mu_{\mathrm{B}}$ and $6.81 \mu_{\mathrm{B}}$ for $\mathbf{1}$ and $\mathbf{2}$, respectively, suggest the presence

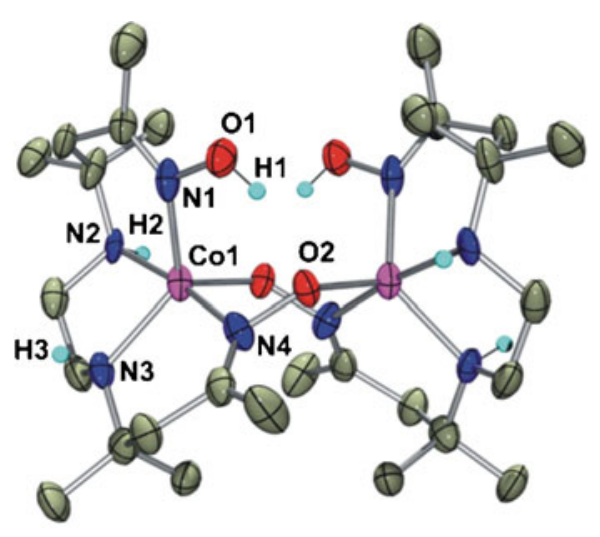

(1)

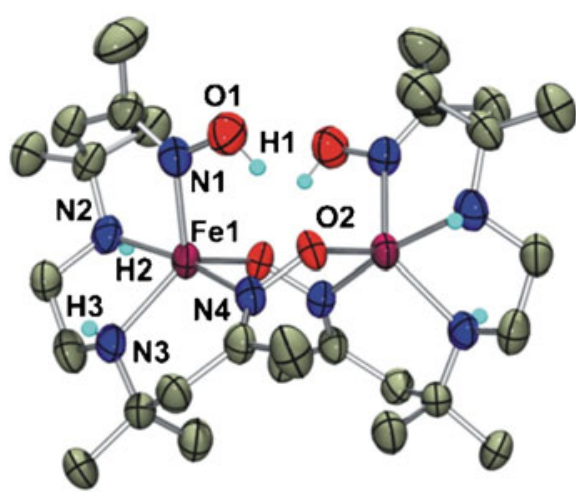

(2)

Figure 1. ORTEP plots (50\% thermal ellipsoids) of the complex cations of $\mathbf{1}$ and 2. 
Table 2. Selected bond lengths $(\AA)$ and angles $\left({ }^{\circ}\right)$ for $\mathbf{1}$ and $\mathbf{2}$.

\begin{tabular}{lrr}
\hline & $\mathbf{1}(\mathrm{M}=\mathrm{Co})$ & $\mathbf{2}(\mathrm{M}=\mathrm{Fe})$ \\
\hline $\mathrm{M}(1)-\mathrm{N}(1)$ & $2.054(7)$ & $2.087(4)$ \\
$\mathrm{M}(1)-\mathrm{N}(2)$ & $2.175(6)$ & $2.134(4)$ \\
$\mathrm{M}(1)-\mathrm{N}(3)$ & $2.076(6)$ & $2.123(4)$ \\
$\mathrm{M}(1)-\mathrm{N}(4)$ & $2.058(7)$ & $2.072(4)$ \\
$\mathrm{M}(1)-\mathrm{O}(2)$ & $1.941(5)$ & $1.940(3)$ \\
$\mathrm{N}(1)-\mathrm{O}(1)$ & $1.393(7)$ & $1.390(4)$ \\
$\mathrm{N}(4)-\mathrm{O}(2)$ & $1.406(7)$ & $1.386(4)$ \\
$\mathrm{N}(1)-\mathrm{M}(1)-\mathrm{N}(2)$ & $92.1(3)$ & $90.00(15)$ \\
$\mathrm{N}(2)-\mathrm{M}(1)-\mathrm{N}(3)$ & $83.0(2)$ & $82.41(15)$ \\
$\mathrm{N}(3)-\mathrm{M}(1)-\mathrm{N}(4)$ & $90.8(3)$ & $87.39(15)$ \\
$\mathrm{N}(4)-\mathrm{M}(1)-\mathrm{N}(1)$ & $91.5(3)$ & $91.23(14)$ \\
$\mathrm{N}(4)-\mathrm{M}(1)-\mathrm{O}(2)$ & $96.3(2)$ & $96.35(12)$ \\
$\mathrm{N}(1)-\mathrm{M}(1)-\mathrm{N}(3)$ & $124.8(2)$ & $119.23(16)$ \\
$\mathrm{O}(2)-\mathrm{M}(1)-\mathrm{N}(2)$ & $87.1(2)$ & $93.48(15)$ \\
$\mathrm{N}(2)-\mathrm{M}(1)-\mathrm{N}(4)$ & $173.7(3)$ & $168.91(15)$ \\
$\mathrm{O}(2)-\mathrm{M}(1)-\mathrm{N}(3)$ & $123.2(2)$ & $129.43(16)$ \\
\hline
\end{tabular}

of moderate to weak exchange coupling between the magnetic centres in dimeric complexes. The room temperature magnetic moment of $\mathbf{3}$ is found to be $5.85 \mu_{\mathrm{B}}$, a value very close to that calculated for a mononuclear high-spin iron(III) complex. Complex $\mathbf{3}$ exhibits a broad band at $665 \mathrm{~nm}$ typical for iron(III)catecholate complex. ${ }^{29}$ The analytical and spectroscopic data leave no doubt about the composition of complexes, 1-3.

\subsection{Crystal structures}

For the structural verification of the complexes, single crystals of $\mathbf{1}$ and $\mathbf{2}$ were grown by layer diffusion of a methanol or acetonitrile solution of complex with diethyl ether. All attempts to crystallize $\mathbf{3}$ were unsuccessful. Complexes $\mathbf{1}$ and $\mathbf{2}$, crystallized in monoclinic space group, are structurally similar. In both the oximate-bridged dimeric complexes, half of the cationic molecule $[\mathrm{M}(\mathrm{HL})]^{+}$is located on a centre of inversion with a perchlorate anion. The metal ions are coordinated by four nitrogen donors from HL and one oximate oxygen (figure 1 ) giving rise to a distorted trigonal bipyramidal coordination geometry $(\tau=0.82$ and 0.66 for $\mathbf{1}$ and $\mathbf{2}$, respectively).

In both the complexes, one amine nitrogen (N3), one imine nitrogen $(\mathrm{N} 1)$ and an oximate oxygen $(\mathrm{O} 2)$ from another ligand of the symmetry related $[\mathrm{M}(\mathrm{HL})]^{+}$ unit occupy the equatorial plane with the M1-N3, M1$\mathrm{N} 1$ and M1-O2 distances of 2.076(6), 2.054(7) and 1.941(5) $\AA$, respectively for 1 and of 2.123(4), 2.087(4), and 1.940(3) $\AA$, respectively for 2 . The other amine nitrogen (N2) and the imine nitrogen (N4) occupy the apical positions with the N2-M1-N4 angle of 173.7(3) for 1 and 168.91(15) for $\mathbf{2}$ (table 2). A similar coordination geometry is observed in oximate bridged dinickel(II) and dicopper(II) complexes of the oxime ligand $\left(\mathrm{H}_{2} \mathrm{~L}\right) .{ }^{17}$

Two metal ions along with two oximate oxygens (O2) and two imine nitrogens (N4) form a six-membered $\mathrm{M}_{2}(\mathrm{NO})_{2}$ core in $\mathbf{1}$ and $\mathbf{2}$. The $\mathrm{M}_{2}(\mathrm{NO})_{2}$ unit adopts a boat conformation as observed in the crystal structures of other dimeric metal complexes of $\mathrm{H}_{2} \mathrm{~L} .{ }^{17}$ This particular binding motif of the ligand forces the metal ions to occupy the positions diagonally on the mean plane formed by two metal ions and two bridging oximate oxygens $(\mathrm{O} 2)$ with the $\mathrm{M} \cdots \mathrm{M}$ distances of $3.739 \AA$ in $\mathbf{1}$

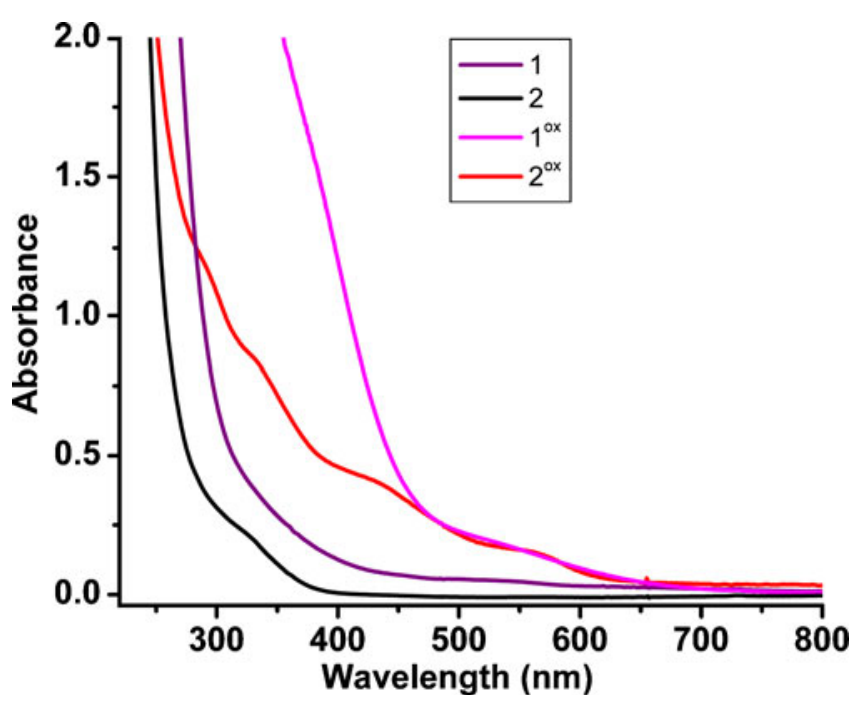

Figure 2. Optical spectra of $\mathbf{1}, \mathbf{1}^{\mathbf{0 x}}, \mathbf{2}$ and $\mathbf{2}^{\mathbf{o x}}$ in acetonitrile $(0.5 \mathrm{mM})$ at room temperature. 


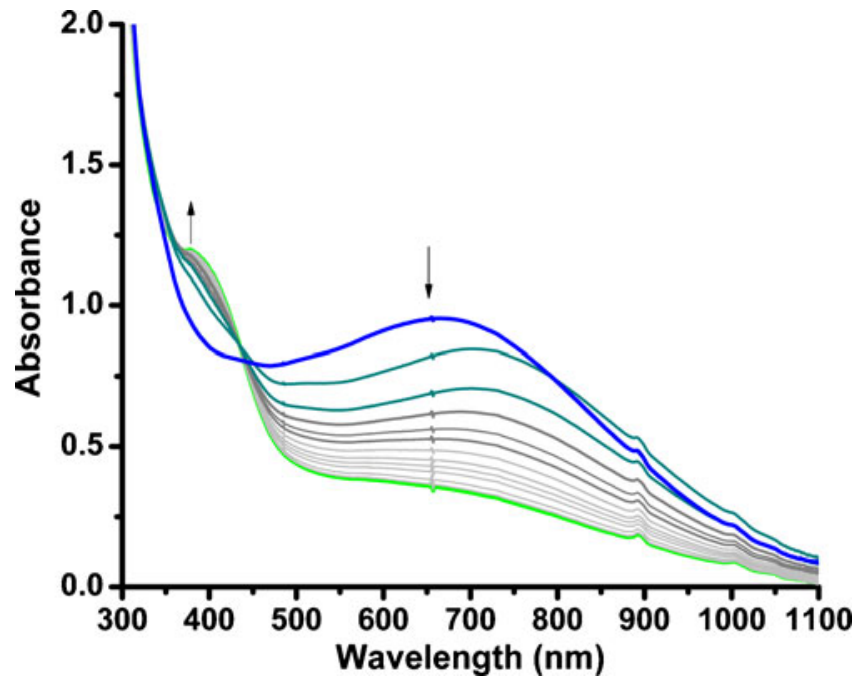

Figure 3. Optical spectral changes during the reaction of $\mathbf{3}$ $(0.5 \mathrm{mM}$ in acetonitrile) with dioxygen at room temperature.

and $3.713 \AA$ in $\mathbf{2}$. Apart from the intermolecular hydrogen bonding involving the complex cations and perchlorate anions, intramolecular hydrogen bonding is also observed between the oximate $(\mathrm{O} 2)$ and oxime oxygen (O1) in the solid-state structure of both the complexes.

\subsection{Dioxygen reactivity}

The dinuclear complexes (1 and $\mathbf{2}$ ) are oxygen sensitive. A light pink solution of complex $\mathbf{1}$ in acetonitrile reacts with dioxygen over a period of $2 \mathrm{~h}$ to form an amber solution. The ESI-MS of the final reaction solution shows peak at $m / z=702.22$ with isotope distribution pattern calculated for $\left[\mathrm{Co}_{2} \mathrm{O}(\mathrm{L})_{2}\right]^{+}$. The optical spectral data (figure 2) along with ESI-MS data indicate a possible formation of hydroxo-bridged dicobalt(III) complex, $\left[\mathrm{Co}_{2}^{\mathrm{III}}(\mathrm{OH})(\mathrm{L})_{2}\right]^{2+}\left(\mathbf{1}^{\mathbf{o x}}\right)$. It is likely that the bridging hydroxide group gets deprotonated in the experimental conditions of ESI-MS. Similarly, the oximate-bridged diiron(II) complex (2) reacts with $\mathrm{O}_{2}$ within $1 \mathrm{~h}$. The featureless optical spectrum of $\mathbf{2}$ is replaced by a new spectrum with shoulders at 330 , 428 and $555 \mathrm{~nm}$. These peaks, by analogy with other oxo-bridged diiron(III) complexes, may be attributed to charge-transfer bands of $\left[\mathrm{Fe}_{2}^{\mathrm{III}} \mathrm{O}(\mathrm{HL})_{2}\right]^{2+}\left(\mathbf{2}^{\mathbf{o x}}\right) .{ }^{30}$ Unfortunately, the final oxidized products could not be isolated for further characterization.

The iron(III)-catecholate complex (3) reacts with dioxygen in acetonitrile at ambient condition over a period of $8-10 \mathrm{~h}$ during which the purple solution slowly turns to a light green solution. The optical spectral changes during the reaction reveal the disappearance of the catecholate-to-iron(III) charge-transfer band at $665 \mathrm{~nm}$ with time at a pseudo-first order rate of $1.20 \times 10^{-4} \mathrm{~s}^{-1}$ (figure 3). The decay of charge-transfer band at $665 \mathrm{~nm}$ suggests the oxidation of 3,5-di-tertbutylcatechol in the reaction of $\mathbf{3}$ with dioxygen.

Analysis of organic products from the reaction solution by ${ }^{1} \mathrm{H}-\mathrm{NMR}$ spectroscopy after separation of metal ion by acidic work-up reveals the formation of catechol derived products. Three $\mathrm{C}-\mathrm{C}$ bond cleavage products from catechol: 4,6-di-tert-butyl-2-pyrone (A), 3,5-di-tert-butyl-2-pyrone (B) and 3,5-di-tert-butyl-5(carboxymethyl)-2-furanone (C) are obtained. In the reaction, $66 \%$ catechol is oxidized to afford about $48 \%$ extradiol cleavage products (A and B) and $7 \%$ intradiol product $(\mathbf{C})$. The autooxidation product of catechol, 3,5-di-tert-butylbenzoquinone (D), is obtained with $11 \%$ yield leaving $34 \%$ unreacted catechol (scheme 2). It is important to mention here that the selectivity of extradiol catechol cleavage is decreased in the presence of an acid or a base. A large number of model complexes show catechol cleavage reactivity, ${ }^{31-33}$ but examples of biomimetic iron-catecholate complexes that show selective extradiol cleavage are limited. ${ }^{33-35}$ Extradiol products have been observed in iron-catecholate complexes of facial $\mathrm{N} 3$ or NNO donor ligands. ${ }^{27,36-42}$ The iron-catecholate complexes of N4 donor ligands have been shown to afford intradiol products. ${ }^{31}$ Complex 3, being an iron(III)-catecholate complex of a tetradentate nitrogen donor ligand, shows extradiol selectivity and thereby mimics the extradiolcleaving catechol dioxygenases.

A lower conversion of catechol cleavage $(66 \%)$ in $\mathbf{3}$ may be attributed to the flexible nature of the oximate

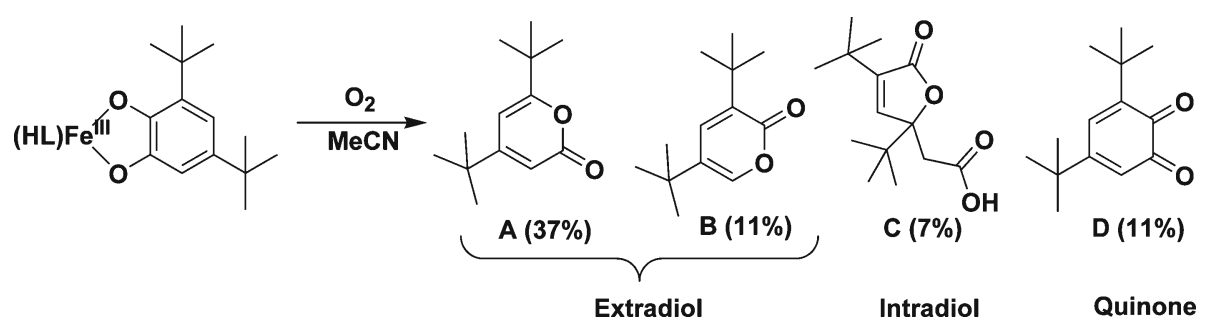

Scheme 2. Catechol cleavage products in the reaction of $\mathbf{3}$ with dioxygen. 


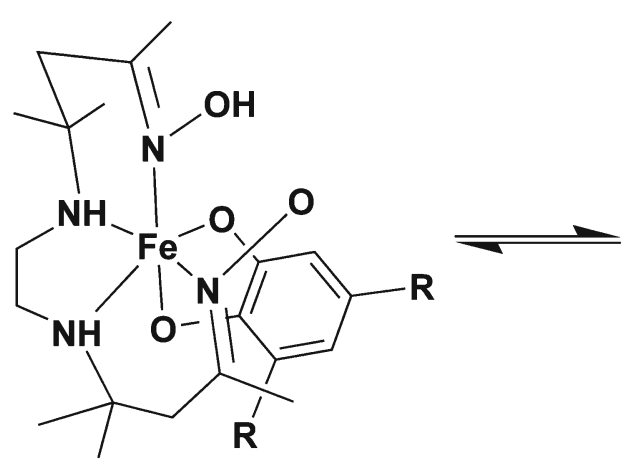

Non-planar HL

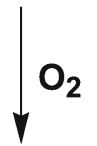

Catechol cleavage<smiles>[R]c1cc([R])c2c(c1)OP1(C(C)(C)C)(N=C(C)CC(C)(C)N1)NCCN2</smiles>

Planar HL

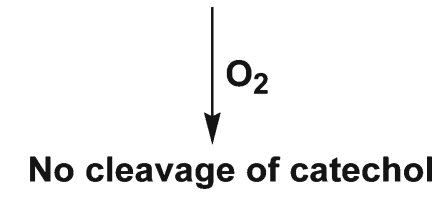

Scheme 3. The effect of conformational flexibility of HL on catechol-cleavage reactivity of 3.

ligand where isomers with both planar and non-planar conformations are expected to be present in solution (scheme 3). The planar orientation of the ligand has been observed in square-planar or octahedral transition metal complexes. ${ }^{17,43,44}$ The isomer with non-planar conformation of the ligand leads to dioxygen activation with concomitant $\mathrm{C}-\mathrm{C}$ bond cleavage of catechol. The extradiol-selectivity clearly suggests that an alkylperoxo intermediate, formed upon dioxygen activation at the iron(II)-semiquinone species, leads to an alkenyl migration. ${ }^{45}$ The isomer with planar conformation of the ligand, on the other hand, binds catechol in a monodentate fashion because it is not geometrically possible for two phenolate oxygens of catecholate ring to occupy the axial positions. In this case the activation of dioxygen does not form an alkylperoxo intermediate to undergo $\mathrm{C}-\mathrm{C}$ bond cleavage of catechol.

\section{Conclusion}

We have isolated and structurally characterized two oximate bridged dinuclear metal complexes where the metal centres are connected by out-of-plane oximate bridge. The dimeric iron(II) and cobalt(II) complexes are oxidized to hydroxo or oxo-bridged dimetallic complexes. A biomimetic iron(III)-catecholate complex is described which activates dioxygen to show oxidative $\mathrm{C}-\mathrm{C}$ bond cleavage of catechol. The extradiol selectivity in the iron(III)-catecholate complex is the first example of a biomimetic system supported by an oxime ligand. The results described in the work highlight the role of ligand flexibility on the dioxygen reactivity of metal complexes.

\section{Supplementary information}

CCDC-833673 (1) and CCDC-833674 (2) contain the supplementary crystallographic data for this paper. The data can be obtained free of charge at www.ccdc.cam.ac.uk/conts/retrieving.html or from the Cambridge Crystallographic Data Center, 12 Union Road, Cambridge CB2 1EZ, UK; Fax: +44-1223/336033; E-mail: deposit@ccdc.cam.ac.uk.

\section{Acknowledgements}

This research was supported by the Department of Science and Technology (DST), Government of India. SC is thankful to the Council of Scientific and Industrial Research (CSIR), India for a fellowship. Crystal structure determination was performed at the DST-funded National Single Crystal Diffractometer Facility at the Department of Inorganic Chemistry, Indian Association for the Cultivation of Science (IACS).

\section{References}

1. Chaudhuri P 2003 Coord. Chem. Rev. 243143

2. Milios C J, Stamatatos T C and Perlepes S P 2006 Polyhedron 25134

3. Milios C J, Raptopoulou C P, Terzis A, Lloret F, Vicente R, Perlepes S P and Escuer A 2004 Angew. Chem. Int. Ed. $\mathbf{4 3} 210$ 
4. Khanra S, Biswas B, Golze C, Büchner B, Kataev V, Weyhermüller T and Chaudhuri P 2007 Dalton Trans. 481

5. Khanra S, Weyhermüller T, Bill E and Chaudhuri P 2006 Inorg. Chem. $\mathbf{4 5} 5911$

6. Chaudhuri P, Weyhermüller T, Wagner R, Khanra S, Biswas B, Bothe E and Bill E 2007 Inorg. Chem. 46 9003

7. Khanra S, Weyhermüller T, Rentschler E and Chaudhuri P 2005 Inorg. Chem. 448176

8. Jiang Y-B, Kou H-Z, Wang R-J, Cui A-L and Ribas J 2005 Inorg. Chem. 44709

9. Khanra S, Weyhermüller T and Chaudhuri P 2007 Dalton Trans. 4675

10. Khanra S, Weyhermüller T and Chaudhuri P 2008 Dalton Trans. 4885

11. Karmakar S, Das O, Ghosh S, Zangrando E, Johann M, Rentschler E, Weyhermüller T, Khanra S and Paine T K 2010 Dalton Trans. 3910920

12. Kukushkin V Y and Pombeiro A J L 1999 Coord. Chem. Rev. 181147

13. Kukushkin V Y and Pombeiro A J L 2002 Chem. Rev. 1021771

14. Garnovskii D A, Pombeiro A J L, Haukka M, Sobota P and Kukushkin V Y 2004 Dalton Trans. 1097

15. Garnovskii D A, Bokach N A, Pombeiro A J L, Haukka M, Fraústo da Silva J J R and Kukushkin V Y 2005 Eur. J. Inorg. Chem. 3467

16. Pavlishchuk V V, Kolotilov S V, Addison A W, Prushan M J, Butcher R J and Thompson L K 2002 Chem. Commun. 468

17. Das O, Adarsh N N, Paul A and Paine T K 2010 Inorg. Chem. 49541

18. Fraser J W, Hedwig G R, Powell H K J and Robinson W T 1972 Aust. J. Chem. 25747

19. Powell H K J and Russell J M 1978 Aust. J. Chem. 31 2409

20. Kee T-S and Powell H K J 1976 Aust. J. Chem. 29921

21. Wolsey W C 1973 J. Chem. Educ. 50 A335

22. Fraser J W, Hedwig G R, Morgan M M and Powell H K J 1970 Aust. J. Chem. 231847

23. Demmin T R and Rogic M M 1980 J. Org. Chem. 45 1153
24. Matsumoto M and Kuroda K 1982 J. Am. Chem. Soc. 1041433

25. Weiner H, Hayashi Y and Finke R G 1999 Inorg. Chim. Acta 291426

26. Mayilmurugan R, Suresh E and Palaniandavar M 2007 Inorg. Chem. 466038

27. Paria S, Halder P and Paine T K 2010 Inorg. Chem. 49 4518

28. Bruker 2006 Version 2.1-0 (Madison, WI: Bruker AXS, Inc.)

29. Cox D D and Que L Jr 1988 J. Am. Chem. Soc. 1108085

30. Kurtz D M Jr 1990 Chem. Rev. 90585

31. Costas M, Mehn M P, Jensen M P and Que L Jr 2004 Chem. Rev. 104939

32. Mayilmurugan R, Visvaganesan K, Suresh E and Palaniandavar M 2009 Inorg. Chem. 488771

33. Bruijnincx P C A, van Koten G and Gebbink R J M K 2008 Chem. Soc. Rev. 372716

34. Wagner M, Limberg C and Tietz T 2009 Chem. Eur. J. 155567

35. Mayilmurugan R, Stoeckli-Evans $\mathrm{H}$ and Palaniandavar M 2008 Inorg. Chem. 476645

36. Lin G, Reid G and Bugg T D H $2001 \mathrm{~J}$. Am. Chem. Soc. 1235030

37. Natarajan A and Palaniandavar M 2010 Dalton Trans. 391195

38. Ito M and Que L Jr 1997 Angew. Chem. Int. Ed. Engl. 36 1342

39. Jo D-H and Que L Jr 2000 Angew. Chem. Int. Ed. Engl. 394284

40. Bruijnincx P C A, Lutz M, Spek A L, Hagen W R, Weckhuysen B M, van Koten G and Gebbink R J M K 2007 J. Am. Chem. Soc. 1292275

41. Paria S, Halder P, Chakraborty B and Paine T K 2011 Indian J. Chem. 50A 420

42. Ogihara T, Hikichi S, Akita M and Moro-oka Y 1998 Inorg. Chem. 372614

43. Daniel E A, March F C, Powell H K J, Robinson W T and Russell J M 1978 Aust. J. Chem. 31723

44. Lynde-Kernell T and Schlemper E O 1988 J. Coord. Chem. 16347

45. Bugg T D H and Lin G 2001 Chem. Commun. 11 941 